the populations of each political area in every year since 1920 (Pp. $x i+621$. New York: United Nations; London: H.M.S.O., 1961). The first chapter entitled "How Well Do We Know the Present Size and Trend of the World's Population?" gives a valuable account of the methods used in preparing population statistics by the United Nations Organization. It is perhaps not always realized that approximately one-half of the world's population is now concentrated in four countries: China, India, the U.S.S.R. and the United States. The Organization assesses the accuracy of the 1953 census for China and suggests that the number of inhabitants of mainland China in that year was between 553 and 612 millions, and in mid-1959 between 605 and 697 millions. This is the population about which there is the maximum degree of uncertainty, India's population is known within 11 millions, and that of the two others within 3 millions. As regards the other areas of the world, it is believed that in most estimates there is a tendency to underestimate rather than overestimate populations, though some errors will no doubt be self-compensating between different territories. Their population is estimated as being between 1,431 and 1,476 millions; the four large areas have populations between 1,416 and 1,508 millions. The world's population in 1959 is believed to be between 2,853 and 2,964 millions, so it is evident that the uncertainty about China is the major factor in the range. The demographers of the United Nations Organization estimate that the annual rate of growth may lie betwoen 1.5 and 2 per cent per annum, resulting in a total annual increase of 44-55 million persons. Tables in the Yearbook include data about the economically active and the illiterate population of different countries, as well as vital statistics dealing with births, marriages and deaths. The rudimentary data on expectation of life in African countries indicate the tremendous scope for mortality reduction that still exists in that continent.

\section{Population Statistics in the United Kingdom}

The Registrar General's Statistical Return for the first quarter of 1961 records nearly 204,000 live births, the highest figure for the first (or any) quarter for more than ten years (No. 449. Pp. 28. London: H.M.S.O., 1961. 2s. 6d. net). Marriages, on the other hand, are fewer at 84,000, compared with 89,000 a year ago. There were 177,000 deaths, giving a relatively high crude death-rate of $15 \cdot 7$, but infant mortality continues to decline, and at 22.9 por thousand births is an all-time low for a first quarter. It will be interesting to see whether the declining trend in the number of marriages will continue, and be followed by a decline in births. The return contains, as is usual in the first quarter, estimates of the home population of administrative counties, boroughs and urban districts at June 30, 1960, together with vital statistics for these areas. In 1960 there were only 22 deaths from poliomyelitis: the lowest number since records began to be kept.

\section{Technical Reports of the U.S. Armed Forces}

Since the Second World War, the Office of Technical Services had been the agent in the Federal Government for the collection, reproduction and sale of reports of Government-sponsored research to firms and organizations not performing contract work for the Department of Defense. The Armed Services Technical Information Agency is the central agency of the Department of Defense, the mission of which is to provide for the efficient interchange of military research and development reports among Department of Defense agencies and their contractors. The number of technical reports of research and development sponsored by the Army, Navy, and Air Force which are made available to the scientific and industrial public is expected to double next year through an extension of the co-operative activities of the Office and the Agency. With the growing volume of Government-sponsored research, the extension of the co-operative work between the Office and the Agency will enable the Office to offer to the public in the next fiscal year 15,000-20,000 technical reports, prepared under military auspices. The Armed Services Technical Information Agency acquires and catalogues almost 30,000 military technical reports each year-about two-thirds of them unclassified. Under the new co-operative programme, the Agency will provide copies of the unclassified reports to the Office, together with catalogue information. A further use of work already carried out by the Agency will be made in the production of the Office's periodical U.S. Government Research Reports, which is used as an announcement medium to inform civilian scientists, engineers, and business men of new reports which are available. The unclassified portion of the Agency's Technical Abstract Bulletin which, so far, has been produced only for activities directly concerned with military research and development, will become a section of the U.S. Government Research Reports, which, from July 1961, will be published twice a month instead of once a month as in the past. Details of the new programme are outlined in the June-July issue of Scientific Information Notes (3, No. 3; June--July, 1961).

\section{The National Lending Library}

A RECENT issue of N.L.L. News, a news-sheet of the National Lending Library for Science and Technology, indicates broadly the types of literature now available from Boston Spa (No. 1; August 1961. Pp. 4. Boston Spa: National Lending Library for Science and Technology, Department of Scientific and Industrial Research, 1961). These include translations of Russian literature, including 'cover-to-cover' translations; Russian books; the 'PB' reports issued by the Office of Technical Services of the U.S. Department of Commerce; the published reports on German industry produced by the British Intelligence Objectives Sub-Committee, the Combined Intelligence Objectives Sub-Committee and the Field Information Agency Technical (U.S.A.); and certain frequently used periodicals in English which were on a list issued from Stanmore. Loan requests for English language serials and books in languages other than Russian should continue to be sent to the Science Museum Library. With the exceptions indicated above, the National Lending Library is not yet providing a general loan service for publications in the English language, but it is expected that in about twelve months time the man-power problems will have been solved and the transfer from the Science Museum Library completed. It is then proposed to make a full-scale survey of the National Lending Library's use, non-use, and of its failures to meet requests with the view of improving its services and promoting the greater use of scientific literature.

\section{The Use of Scientific Literature}

THE Library Association Record for August 1961 contains an article on "The Use of Scientific Litera- 